\title{
Integrated Design Studios: Education to Overcome Silo-thinking and Enable Full BIM-exploitation in AEC
}

\author{
Michael Filzmoser ${ }^{1 *}$, Iva Kovacic ${ }^{2}$, and Dragos-Cristian Vasilescu ${ }^{3}$
}

\begin{abstract}
Building Information Modeling (BIM) related promises are numerous - reduction of the architecture, engineering and construction (AEC) industry fragmentation, construction cost, and delivery time, as well as lifecycle optimization have been advocated in both literature and practice. But so are the challenges of BIM adoption: establishment and standardization of BIM data structures or ensuring the necessary skills and competencies for planning process participants. In this paper we present ongoing research on the integration of BIM in education through student experiments, based on a BIM-supported integrated design studio (IDS). Thereby the various features of BIM technology adopted in multidisciplinary conceptual design stage are explored and evaluated. Quantitative and qualitative research, in form of questionnaires and focus group discussions, addresses the people and process related challenges in such collaborative BIMsupported building projects. The analysis of three cycles of such IDSs has shown that the participants appreciate the collaborative approach, and benefit from working with other disciplines by sharing knowledge; however BIM technology has not significantly contributed to the improvement of the design quality.
\end{abstract}

\section{Keywords}

integrated design studio, BIM, integrated planning, experiment

\footnotetext{
${ }^{1}$ Vienna Institute of Technology, Institute of Management Science, Vienna, Austria. *Corresponding Author: E-mail: michael.filzmoser@tuwien.ac.at (address: Michael Filzmoser, Theresianumgasse 27, 1040 Vienna, Austria)

${ }^{2}$ Vienna Institute of Technology, Institute of Interdisciplinary Construction Process Management, Vienna, Austria, iva.kovacic@tuwien.ac.at

${ }^{3}$ Vienna Institute of Technology, Institute of Management Science, Vienna, Austria, dragos.vasilescu@tuwien.ac.at
} 


\section{Introduction}

Adoption of Building Information Modeling (BIM) as well as the establishment and standardization of BIM data structures is currently a central issue for the EU public policy in the construction and public project delivery. The BIM related promises advocated in literature are numerous, such as the reduction of: industry fragmentation in the architecture, engineering and construction (AEC) industry, construction costs, delivery times, $\mathrm{CO}_{2-}$ emissions and in general to achieve aims of sustainability (Eadie et al., 2013; Dainty et al., 2015). These aims are only to be achieved through reduction of fragmentation of the heterogeneous, small scale industry, for which BIM seems to be a vehicle. Amongst others, an integration of the separated disciplines in the fragmented building industry is mandatory to unravel the creative potential of the partners cooperating in construction projects. BIM could be an instrument that enhances integrated planning by closer cooperation of the different disciplines, as it allows collaboratively establishing and working on joint building models, which can be used for various purposes - like architectural modeling, structural analysis, thermal simulation, or life-cycle optimization. However, research shows that the potential of BIM as catalyst for integrated practice, are not realized yet to its full extent. The two main problems observed by Kovacic and Filzmoser (2014) were: (i) individuals (planning disciplines) seem to be constricted by separated roles and thinking patterns, which causes a lack of sense for interdisciplinary cooperation (Chien et al., 2014) even when working in a team, and (ii) software is either not interoperable, or modeling conventions for joint use of models would be required, but are missing.

Similar issues have been mentioned in literature, regarding not only experience with students but also industry. The lack of software interoperability is an issue of tremendous importance for

\footnotetext{
${ }^{4}$ Note that the results of the current winter term $15 / 16$ "BIM factory" are not yet analyzed and therefore only data of the first three iterations is presented in this paper.
}

collaboration and even causes mistrust of BIM supported design (Jeong et al., 2009; Amor and Ma, 2006). Kiviniemi et al. (2005) state that one of the main problems of the different software packages is that they do not fully support the information needs for the entire design and planning process. With this respect, there are many similarities between industry and classroom, which requires process-specific modeling as well as datatransfer conventions and standards.

These examples demonstrate the numerous challenges that need to be tackled for the successful implementation of BIM. First of all the skills of the planning process participants need to be adapted to the changed BIM-supported interdisciplinary planning process. This requires the installation of BIM-based courses in the university curricula. Moreover, the reduction of BIM to the technological realm has not brought the expected benefits yet. Innovation of the architecture engineering and construction industry processes is closely related to successful implementation of BIM on all levels: technology, people and process.

The aim of the project presented in this paper is to design and continuously improve a course on BIMsupported integrated design. The research question we address is: How has a university course on BIM-supported integrated design need to be configured to ensure satisfaction of the participants, functionality of modeling and simulation software and therefore optimal learning experience and outcomes. Through a so called integrated design studio (IDS) at the Vienna University of Technology we address these open challenges of integrated BIM-supported design and construction in education. The IDS course is now at its fourth iteration "BIM factory" - an interdisciplinary building design project of production and office facilities for a medium sized mechanical engineering company. The student experiments, based on such multidisciplinary, collaborative design courses allow exploring and evaluating various features of BIM technology, such as data exchange, interfaces and workflows 
between various software platforms and related errors due to misinterpretation of geometry or semantic modeling differences, in a controlled laboratory setting. Quantitative (questionnaires), and qualitative (focus group discussions) methods generate additional data for the analyses of the research questions of this paper: (i) What are the major technology-, people- and process-related challenges for the successful adoption of BIM in interdisciplinary building design projects, and how are they addressed best, and (ii) if there is a correlation between BIM usage and improvements in the planning processes and team performance.

The remainder of this paper is structured as follows: Section 2 describes the course design for the three iterations, Section 3 describes the study design and the data gathering methods, Section 4 presents the results of the analyses of the three iterations of interdisciplinary BIM-supported building design courses and Section 5 discusses these results in light of the research questions of this paper.

\section{Course Design}

To address the challenges mentioned above, as well as to introduce BIM into the curricula IDS, as BIM supported multidisciplinary design course platform was established at the Vienna University of Technology. The project teams involved are composed of students of architecture, civil engineering and building science, working in collaborative manner, using discipline-specific BIM tools for architectural modeling, REFM analysis or thermal simulation and analysis. The assignments start with a joint development of conceptual design (mostly starting with analogous design workshop, using physical models), over first basic modeling in architectural software (Revit, Allplan or Archicad) and data transfer to follow-up tools for or structural engineering (Dlubal REFM, Scia) and heating, ventilation and air conditionsing (HVAC) (Plancal, Revit MEP) as well as to thermal analysis (via Sketch Up to Energy Plus).

The task of the teams was to develop a preliminary integrated design, consisting of the architectural and functional design, load bearing structure, HVAC (ventilation) and energy design, together with a proof of the concept used (simulation and optimization). Therefore, the teams had to finally deliver an architecture model including the structural design, thermal and ventilation models (as representative of HVAC), as well as the thermal simulation and energy certificate. The courses were supported by software education workshops, provided by the software vendors, which also gave feedback and helped with software-specific problems throughout the courses.

The assignments changed between iterations from winter term 2012/13 to winter term 2014/15:

1. Iteration BIM_sustain: Sustainable office building

2. Iteration BIM_station: Multi functional event-center

3. Iteration BIM_meridian: Temporary housing on various locations along $16^{\circ}$ meridian

In each iteration different students from architecture, civil engineering and building science participated in the IDS to fulfill curricula requirements. This ensures on one hand a similar setting for students across iterations in experiencing interdisciplinary working and BIM experience and on the other hand provides the course lecturers with a platform allowing for comparison of the results across the iterations. The main focus in problem solving from first to second iteration was to improve the design process and software interoperability - lacking interoperability was identified as the most important problem and therefore prioritized. As a result, in the second iteration only interoperable software combinations were used - based on experience gathered in the first cycle.

Group decision-making models such as those of Hackman and Morris (1975) and Simon (1960) imply on cognitive conflicts arising from different cognitive assumptions of the group members even if they share the same goals - a situation we observe in an IDS. Furthermore, Rohrbaugh (1988) identifies four stages in such interaction processes: elicitation, negotiation, exploration and finally evaluation. In the stages elicitation and negotiation 
differences are of primary concern, whereas, during exploration and evaluation the focus shifts to integration of shared goals. Thereby establishment of teams with shared goals is important to reach the stages of joint evaluation and achievement of these determined goals. A teaming workshop at the beginning of the design class was introduced, for this reason, to establish team spirit and support the development of common goals in the team. Furthermore, interdisciplinary intermediate presentations were introduced.

From the second to the third iteration we tried to improve the project quality, as it was observed that this was the major issue for the project delivery. As the multidisciplinary design course introduced several new challenges - innovative design, new design-tools and functionalities (BIM) and interdisciplinary collaboration (Kovacic et al., 2015) the students were overstrained trying to solve three new challenges simultaneously - as result we observed poor design quality and sequential work-flows following the "form follows software" approach.

In order to improve the design quality, which was the main aim of the third iteration, we tried to reduce the level of complexity - which was reported as a major problem by the students throughout the design course - on several levels: on level of design-assignment; as well as on the level of design and modeling process.

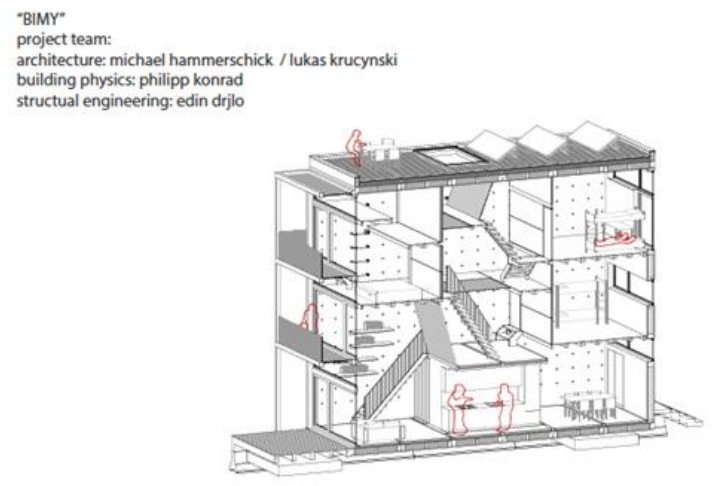

Figure 1. Temporary housing model in Archicad, 3. Iteration, WS 14/15
In the first two iterations exact spatial and functional programs with prescribed space-areas were given to the students, as it is the case in the architectural competitions or real-life design projects. The projects were quite large $-5.500 \mathrm{~m}^{2}$ Gross Floor Area for the office building, respectively $3.000 \mathrm{~m}^{2}$ GFA for the event-center grasping of the spatial program and organizing the functions was quite challenging for the students in terms of time and effort, and the remaining temporal resources and motivation insufficient for high-quality BIM modeling and simulation. Therefore by introducing a temporary housing project in the third iteration (Figure 1), with the only fixed constraint being a maximum size of 500 m3 Gross Floor Volume. We allowed for a certain level of integrity and self-determination in the design-definition as well as in design-organization as the location and functional program could be defined by the students themselves. Furthermore, evaluation sheets were handed out, where students could define and prioritize the project goals (reduction of emissions, land consumption, accessibility, use of renewable materials etc.), and focus and reflect on the progress of achievement of these, as the project evolves. We addressed the streamlining of the BIM modeling and data exchange process through data exchange trainings and instructions for the creation of modeling conventions within the groups, thus reducing the modeling effort and increasing the data exchange success.

Finally, the main difference between the first two and the third cohort is the cancellation of the HVAC modeling (represented through ventilation) in the third cycle. This has several reasons - the instructor team does not have sufficient skills in HVAC design and modeling software. Therefore external lecturers as well as software company Plancal had to be involved in the course, which proved to cause additional effort to already overburdened course-program.

The participants in the three iterations of the IDS, per discipline and in total are represented in Table 1. This table also includes the participants in the questionnaires and focus-group discussions applied for the evaluation of the IDS and there resulting response rates. 
Table 1: Course and evaluation participants

\begin{tabular}{lllllll}
\hline semester & architecture & $\begin{array}{l}\text { civil } \\
\text { engineering }\end{array}$ & $\begin{array}{l}\text { building } \\
\text { science }\end{array}$ & total & response & response rate \\
\hline $\begin{array}{l}\text { winter term } \\
12 / 13\end{array}$ & 9 & 11 & 15 & 35 & 32 & $91.4 \%$ \\
$\begin{array}{l}\text { winter term } \\
13 / 14\end{array}$ & 13 & 8 & 23 & 44 & 32 & $72.7 \%$ \\
$\begin{array}{l}\text { winter term } \\
14 / 15\end{array}$ & 18 & 4 & 8 & 30 & 24 & $80.0 \%$ \\
\hline
\end{tabular}

Table 2 presents the course development over the three iterations: Varying number of ECTS per cohort and discipline, the tasks, team building strategy, and the used software. The main differences were the increase in the number of credits for the architects, the introduction of the teaming workshop in the second iteration, and the reduction of planning tasks by cancellation of HVAC modeling in the third iteration. In all three iterations the project duration was one whole semester which is equivalent to 14 weeks; one ECTS is equivalent to 25 hours work.

The IDS course is an elective and not mandatory for students of any of the three disciplines. We can therefore conclude that the students that joined each of the three iterations did so, based on their own interest and motivation.

To conclude, to improve dealing with complexity within the multidisciplinary design task, we aimed to simplify the design-assignment by reducing the project size and giving the students more freedom in design-definition. However we supported the design-optimization through definition of indicators (main project goals) and further on through streamlining of the modeling process by providing conventions and data exchange standards.

\section{Methodology}

Though the task and the experimental settings changed throughout the three iterations, the same approach for evaluating the experiments, by a combination of quantitative and qualitative analyses, was applied. The quantitative part consisted of two questionnaires which were handed out at the end of the project: the satisfaction questionnaire addressed the integrated planning process with the constructs 'satisfaction with the process', 'satisfaction with the outcome' and 'satisfaction with the cooperation'; information for each construct being elicited with four questions on a 5-point Likert scale (1 low to 5 high) each. On the other hand the software questionnaire addressed the BIM software used in the project and consisted of the two major dimensions: 'ease of use' and 'usefulness' of the technology acceptance model (Davis, 1989). Furthermore we apply a newly developed 'interoperability' construct to evaluate the import/export and data exchange functionality of the BIM-software. Each of these three software constructs was elicited with six questions on a 5 point Likert scale (1 low to 5 high). The construct on process satisfaction was omitted due to a lack of construct validity (Cronbach alpha below .7). Moreover to achieve a satisfactory construct validity for the 'constructs interoperability' and 'ease of use', for both constructs 2 of the 6 items were omitted.

Besides these quantitative evaluations of the planning process and the BIM-software, focus group discussions were used for a qualitative and detailed analysis of the experiments (Krueger and Casey, 2009). Such discussions collect qualitative data, both deeper and broader than interviews or open question questionnaire data due to group dynamics, from a relatively homogeneous group on a specific topic. 
Table 2: Overview of three cycles with credits, tasks and software

\begin{tabular}{|c|c|c|c|}
\hline & $\begin{array}{c}\text { first iteration } \\
\text { winter term } \\
2012 / 13 \\
\end{array}$ & $\begin{array}{c}\text { second iteration } \\
\text { winter term } \\
2013 / 14 \\
\end{array}$ & $\begin{array}{c}\text { third iteration } \\
\text { winter term } \\
2014 / 15 \\
\end{array}$ \\
\hline ECTS & $\begin{array}{l}\text { civil engineering } 6 \text { ECTS } \\
\text { architecture } 2 \text { ECTS } \\
\text { building science } 10 \text { ECTS }\end{array}$ & $\begin{array}{l}\text { civil engineering6 ECTS } \\
\text { architecture } 5 \text { ECTS } \\
\text { building science } 10 \text { ECTS }\end{array}$ & $\begin{array}{l}\text { civil engineering } 6 \text { ECTS } \\
\text { architecture } 5 \text { ECTS } \\
\text { building science } 10 \text { ECTS }\end{array}$ \\
\hline task & $\begin{array}{c}\text { design of a low-energy } \\
\text { office } \\
\mathrm{GFA}=7.500 \mathrm{~m}^{2}\end{array}$ & $\begin{array}{l}\text { design of a cultural centre } \\
\qquad \mathrm{GFA}=3.000 \mathrm{~m}^{2}\end{array}$ & $\begin{array}{c}\text { design of temporary } \\
\text { housing unit along } 16^{\circ} \\
\text { meridian }\end{array}$ \\
\hline contact time & \multicolumn{2}{|c|}{$\begin{array}{l}\text { weekly meeting of the course instructors with each team, } \\
\text { plus software training units }\end{array}$} & $\begin{array}{c}\text { weekly meeting of the } \\
\text { course instructors with } \\
\text { each team }\end{array}$ \\
\hline presentations & \multicolumn{2}{|c|}{$\begin{array}{l}\text { two intermediate presentations, } \\
\text { one final presentation }\end{array}$} & $\begin{array}{c}\text { two intermediate } \\
\text { presentations, one final } \\
\text { presentation; plus quality } \\
\text { check workshops (Solibri) }\end{array}$ \\
\hline evaluation & \multicolumn{2}{|c|}{$\begin{array}{l}25 \% \text { joint model } \\
25 \% \text { discipline related model } \\
25 \% \text { integrated concept quality } \\
25 \% \text { interdisciplinary collaboration }\end{array}$} & \\
\hline team building & $\begin{array}{l}\text { predetermined by course } \\
\text { instructors based on } \\
\text { software skills and } \\
\text { predefined software } \\
\text { constellations }\end{array}$ & $\begin{array}{l}\text { team building workshop, } \\
\text { free choice of team }\end{array}$ & $\begin{array}{l}\text { team building workshop, } \\
\text { free choice of team }\end{array}$ \\
\hline $\begin{array}{l}\text { software } \\
\text { selection }\end{array}$ & $\begin{array}{l}\text { predetermined by } \\
\text { instructors, based on } \\
\text { student software skills }\end{array}$ & $\begin{array}{l}\text { free choice of modeling } \\
\text { software constellation as a } \\
\text { team }\end{array}$ & $\begin{array}{l}\text { free choice of modeling } \\
\text { software constellation as a } \\
\text { team }\end{array}$ \\
\hline software used & $\begin{array}{l}\text { Revit, Archicad, Allplan } \\
\text { Scia, REFM, Sofistik } \\
\text { TAS, Archicad, Dialux } \\
\text { Plancal, Revit MEP }\end{array}$ & $\begin{array}{l}\text { Revit, Archicad, Allplan } \\
\text { Scia, REFM, } \\
\text { energyPlus, Archicad } \\
\text { Plancal, Revit MEP }\end{array}$ & $\begin{array}{l}\text { Revit, Archicad, Allplan } \\
\text { Scia, REFM, } \\
\text { energyPlus, Archicad }\end{array}$ \\
\hline
\end{tabular}

We grouped together the members from one discipline, i.e. all architects, civil engineers and building scientists and discussed together. This also allowed for an exchange of information and experience among the discipline members, which worked in their separate groups during the project. After the initial question: "How did you experience the interdisciplinary BIM course?" the moderator focused on active listening and just intervened with

5 Duration of focus group discussions in winter term 2012/13: architecture $74 \mathrm{~min}$, civil engineering $88 \mathrm{~min}$, building science $56 \mathrm{~min}$; in winter term 2013/14: questions - not yet addressed - if the discussion stopped. The list of these follow up questions is provided in the appendix. The duration of the nine focus group discussions varied due to different numbers of participants and varying intensity of their participation and discussion. ${ }^{5}$

All focus group discussions were recorded, transcribed and their content analyzed following

architecture $64 \mathrm{~min}$, civil engineering $53 \mathrm{~min}$, building science $46 \mathrm{~min}$; and in winter term 2013/14: architecture $60 \mathrm{~min}$,civil engineering $49 \mathrm{~min}$, building science $70 \mathrm{~min}$. 
the procedure suggested by Srnka and Koeszegi (2007) by two independent coders. First the content was subdivided into thought units that convey single and coherent information, in a next step a category scheme was developed based on theory and the analyzed data (the categorization step). Lastly, the thought units were assigned to these categories. The category scheme used for the coding of the content of the focus group discussions is presented in Table 3 with a description of the category and examples from the focus group discussions.

\section{Results}

The unique feature of the presented set of lab experiments on BIM-supported design projects is the longitudinal nature of the data gathered which allows to analyze the effects of varying course designs based on stable measurement procedures i.e. questionnaires and focus group discussions.

Figure 2 shows the results of the analyses of the software questionnaire for the three iterations and the three involved roles as well as total scores. ${ }^{6}$ As mentioned above, the considered constructs were: (i) ease of use, (ii) usefulness, and (iii) interoperability of the design and analysis software tools used in the group for the purpose of the interdisciplinary building design project. The ease of use does not vary much between the iterations and disciplines and is on average evaluated lower than the usefulness of the applied software tools, though incrementally higher than the interoperability of software, which is rated worse. However, the restriction of used software and software combinations, that are known to be more qualified for interdisciplinary data exchange through better support of IFC standards from the first to the second and third iteration of the course, can be observed in the answers to the questionnaires.

Though only minor changes in the applied software took place the evaluation of their interoperability was higher in the later iterations of the course

\footnotetext{
${ }^{6}$ Note that per row the variable indicated in the label of the $y$-axis is analyzed for the different disciplines as well
}

especially to the improving evaluation of architects and civil engineers. The usefulness of the BIM software was rated constantly high by the participants, which thereby honor the support they receive from BIM technology in performing their tasks in the interdisciplinary building design project.

Figure 3 visualizes the analyses of the satisfaction questionnaire, which was distributed after the interdisciplinary building design project as well. Box-plots for all disciplines and each discipline separately for the three iterations represent the distribution of the average answers to the construct questions for (i) outcome satisfaction, and (ii) cooperation satisfaction.

As it can be seen from Figure 3, the participants were most satisfied with how the planning process worked, with an increasing tendency over the iterations of the course. This last effect was especially due to the higher satisfaction of the architects in the teams, which seemed to benefit most from the input they received from the other disciplines due to the change in the process after the first iteration - i.e. the introduction of the teaming event and the joint design week at the beginning of the project. For the civil engineers and building scientist process satisfaction stayed constant at a high level. Satisfaction with the outcome of the project ranged second highest with quite stable satisfaction values. Interestingly the satisfaction with the cooperation in the team decreased over the iterations of the project. This is driven especially by the low evaluation of the architects which like the process, maybe because they assume a leading and coordinating position within the group, but also stated in the group discussions that they feel under pressure to deliver their models and restricted by the other involved disciplines already very early in the design phase. A second effect to mention here is the decreasing satisfaction of civil engineers over the iterations of the course, which might be due to the time pressure induced by late delivery of the architectural models, unlike the architect situation. This was,

as over all disciplines in Figure 2 and Figure 3. The variables are measured through the questionnaire on a 5point Likert scale ranging from 1 (low) to 5 (high). 


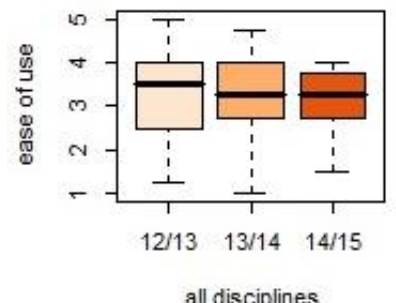

all disciplines

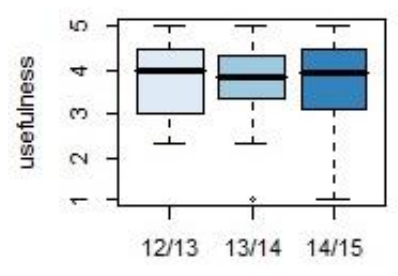

all disciplines

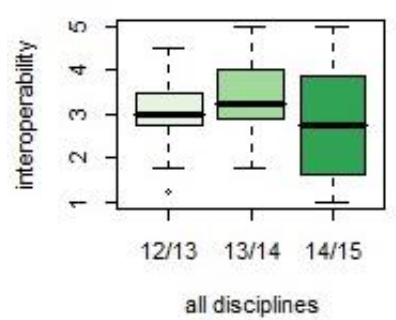

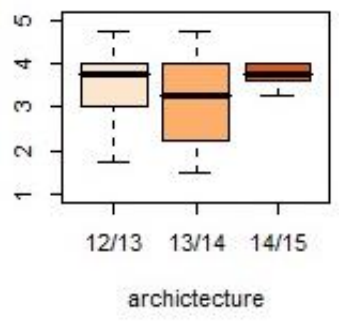

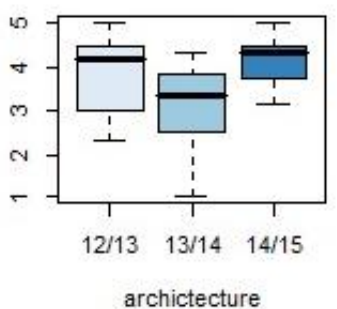

archictecture

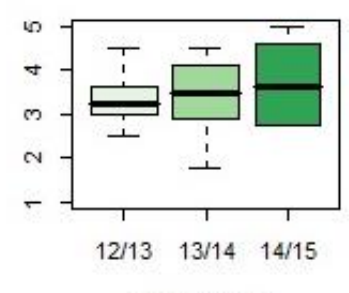

archictecture
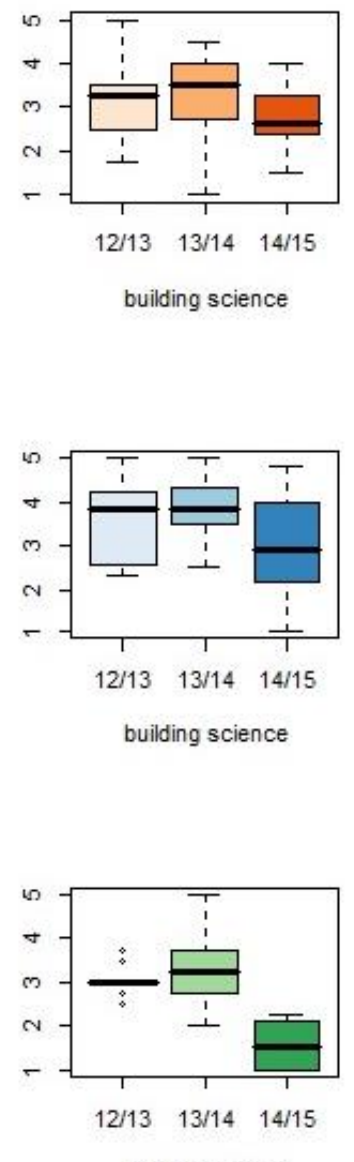

building science
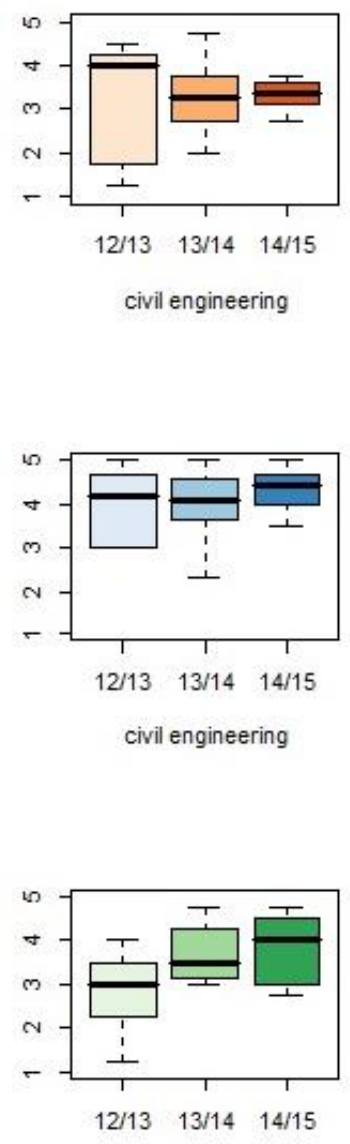

civil engineering

Figure 2: Software questionnaire results

however, no significant topic in the focus group discussions. Participants are quite satisfied with the outcomes they reached and this does not vary much across disciplines or the iterations of the course.

With these two factors - course and discipline - of dependent variables each with three values $(12 / 13$, 13/14 and 14/15 for course and architecture, civil engineering and building science for discipline) resulting in a total of nine groups - and metric independent variables for satisfaction with cooperation (SC) and satisfaction with outcome (SO) as well as ease of use (EU), usefulness (UF) and interoperability (IO) of the software, an analysis of variance (anova) is adequate for the analysis of the data. Table 4 reports the descriptive statistics for the nine groups in these five dependent

${ }^{7}$ Results of the Shapiro-Wilk normality tests for SC: $\mathrm{W}=0.9665, \mathrm{p}<0.05$; for $\mathrm{SO}$ : $\mathrm{W}=0.96344, \mathrm{p}<0.05$; for variables, i.e. the constructs of the evaluation questionnaire.

Checking the preconditions for anova we conducted Shapiro-Wilk tests of normal distribution of the dependent variables. These tests indicated that the distributions of all five dependent variables in the study significantly deviate from normal distribution at $\mathrm{p}<0.05{ }^{7}$ However, as the analysis of variance is robust to deviation from the normality assumption we also check for the other two prerequisites (equality of variances homoscedasticity - between groups and normal distribution of the residuals). The Levene test of equality of variances between the nine groups resulted in homogen variances for $\mathrm{SC}(\mathrm{df}=8$, $\mathrm{F}=0.8228, \mathrm{p}=0.5849)$ and $\mathrm{SO}(\mathrm{df}=8, \mathrm{~F}=1.6671$,

EU: $W=0.9658, p<0.01$; for UF: $W=0.9326, p<0.001$ and for IO: $\mathrm{W}=0.9740, \mathrm{p}<0.05)$. 
The Engineering Project Organization Journal (August 2017) 7, 1

Table 3: Category scheme for the content analysis

\begin{tabular}{|c|c|c|}
\hline category & description & example \\
\hline BIM general & general discussion about BIM projects & $\begin{array}{l}\text { 'I found it great, the design process; } \\
\text { this is something we do not } \\
\text { experience so often during the } \\
\text { studies.' }\end{array}$ \\
\hline collaboration cons & negative experiences in the collaboration & $\begin{array}{l}\text { 'I need the geometry to go further } \\
\text { with simulation ... they are still } \\
\text { forming geometry ... our job } \\
\text { depends on their job.' }\end{array}$ \\
\hline collaboration pros & positive experiences in the collaboration & $\begin{array}{l}\text { 'They supported me at the } \\
\text { beginning of the project when I had } \\
\text { not that much time.' }\end{array}$ \\
\hline confirmation & confirmation of statements from others & 'Mhm, it seems exactly like that.'c \\
\hline course & $\begin{array}{l}\text { grading, content and organization of the } \\
\text { course }\end{array}$ & $\begin{array}{l}\text { 'I think the crits were really } \\
\text { helpful.' }\end{array}$ \\
\hline ease of use & $\begin{array}{l}\text { ease or difficulty of the use of software } \\
\text { functions }\end{array}$ & $\begin{array}{l}\text { 'But in SCIA changing something } \\
\text { was super easy."’a }\end{array}$ \\
\hline interoperability & statements about import, export, interfaces & $\begin{array}{l}\text { 'There was no exchange with the } \\
\text { programs it was not possible and if } \\
\text { it were possible it would take too } \\
\text { much time.'c }\end{array}$ \\
\hline miscellaneous & off topic discussion & e.g. weather \\
\hline moderation & $\begin{array}{l}\text { follow-up questions and active listening by } \\
\text { the moderator }\end{array}$ & $\begin{array}{l}\text { 'Was this equal in the other } \\
\text { groups?'c }\end{array}$ \\
\hline support & software support by software developers & $\begin{array}{l}\text { 'I had an error when I wanted to } \\
\text { make an opening in the ceiling, but } \\
\text { the opening was invisible. So I } \\
\text { contacted the support ...'a }\end{array}$ \\
\hline technical discussion & discussion of technical details (e.g. statics) & $\begin{array}{l}\text { 'Which finite element net size did } \\
\text { you choose?'a }\end{array}$ \\
\hline training & $\begin{array}{l}\text { statements about BIM workshop and } \\
\text { software trainings }\end{array}$ & $\begin{array}{l}\text { 'Our REVIT training took two days } \\
\text { and was very good. We learned a } \\
\text { lot and could ask questions.' }{ }^{\text {b }}\end{array}$ \\
\hline usefulness & effectiveness of the software & $\begin{array}{l}\text { '... it was interesting to see what } \\
\text { SOLIBRI is capable of.' }\end{array}$ \\
\hline
\end{tabular}

${ }^{a}$ focus group discussions 12/13 (BIM_sustain), ${ }^{b}$ focus group discussions 13/14 (BIM_station)

cfocus group discussions 15/15 (BIM_meridian)

The Engineering Project Organization Journal

(C)2017 Engineering Project Organization Society

www.epossociety.org 

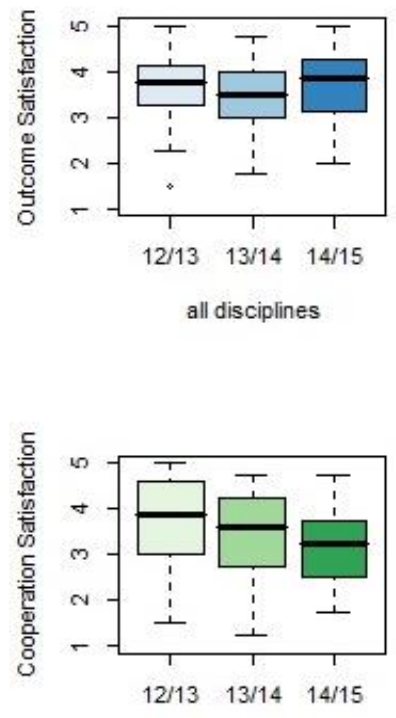

all disciplines
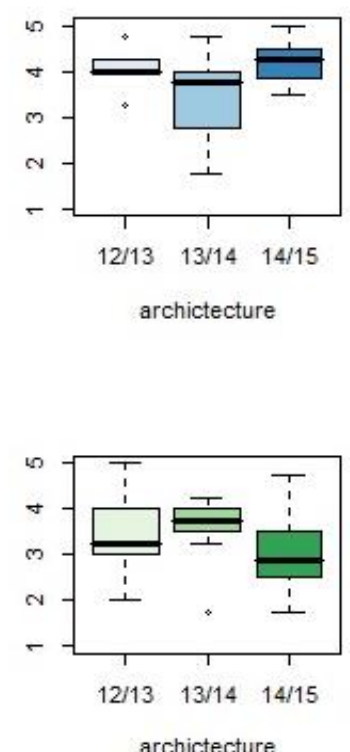
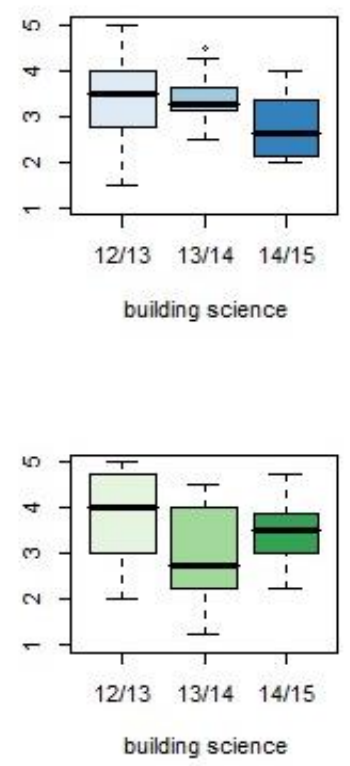
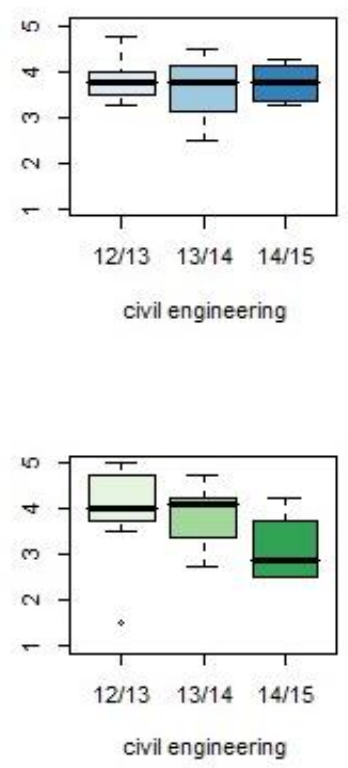

Figure 3: Satisfaction questionnaire results

$\mathrm{p}=0.1196)$. However, for the three software constructs $\mathrm{EU}(\mathrm{df}=8, \mathrm{~F}=2.6742, \mathrm{p}<0.01), \mathrm{UF}(\mathrm{df}=8$, $\mathrm{F}=1.8557, \mathrm{p}=0.07)$ and $\mathrm{IO}(\mathrm{df}=8, \mathrm{~F}=3.0642$, $\mathrm{p}<0.01)$ the group variances differed significantly. Two-factorial anova therefore was only used for the two satisfaction measures. The residuals of the resulting models were normally distributed according to an inspection of the histograms of the residuals. Also Shapiro-Wilk tests indicated the normal distribution of the residuals of the model for $\mathrm{SC}(\mathrm{W}=0.9826, \mathrm{p}=0.2845)$ and $\mathrm{SO}(\mathrm{W}=0.9917$, $\mathrm{p}=0.8547)$.

The anova for SC and SO was accompanied by Tukey post hoc tests of group differences. For the software constructs we use Kruskal-Wallis tests for a non-parametric anova of the nine groups followed by pairwise comparisons using Wilcoxon ranked sum test and Bonferoni-Holm correction for alpha error accumulation as post hoc tests.

A two-factorial anova was conducted to compare the main effects of the course (12/13, 13/14 and 14/15) and discipline (architects, civil engineers and building scientists) and the interaction effect between course and discipline on the satisfaction with the cooperation. The effect of the course year was not significant $(\mathrm{F}(2,79)=2.2731, \mathrm{p}=0.1097)$ indicating no difference in satisfaction with cooperation between the courses 12/13, 13/14 and
$14 / 15$. Also the effect of the discipline was not significant $(\mathrm{F}(2,79)=1.1681 \mathrm{p}=0.3163)$ so that there is no difference between the disciplines in their satisfaction with cooperation. Furthermore the interaction effect was insignificant $(\mathrm{F}(4,79)=1.3606, \quad \mathrm{p}=0.2552)$ and consequently Tukey's HSD post hoc tests only yielded insignificant differences between the three groups.

Similarly for the satisfaction with the outcome a two-way anova was conducted for the main effects of course and discipline and their interaction. The satisfaction with the outcome significantly varied with the discipline $(\mathrm{F}(2,79)=7.3593, \mathrm{p}=0.0012)$. The interaction effect was significant $(\mathrm{F}(4,79)=2.7599, \mathrm{p}=0.0333)$. The course year, however, had no significant influence on satisfaction with outcome $(\mathrm{F}(2,79)=0.7030$, $\mathrm{p}=0.4981$ ). Tukey's HSD post hoc tests indicated, that in 14/15 civil engineers (adjusted $\mathrm{p}=0.0882$ ) and architects (adjusted $\mathrm{p}<0.001$ ) were significantly more satisfied with the outcome than the building scientists. This also holds true for the disciplines over all three iterations were civil engineers have 0.41 more points on this measure $(\mathrm{p}=0.073)$ and architects $0.63(\mathrm{p}=0.001)$. A reason might be that the main tasks of the building scientists were at the end of the project and semester so they suffered time pressure which 
The Engineering Project Organization Journal (August 2017) 7, 1

Table 4: Descriptive statistics for the dependent variables

\begin{tabular}{|c|c|c|c|c|c|c|}
\hline year & discipline & $\mathrm{SC}$ & SO & EU & UF & IO \\
\hline & & $\begin{array}{l}\text { mean } \\
\text { (std. dev.) }\end{array}$ & $\begin{array}{l}\text { mean } \\
\text { (std. dev.) }\end{array}$ & $\begin{array}{l}\text { mean } \\
\text { (std. dev.) }\end{array}$ & $\begin{array}{l}\text { mean } \\
\text { (std. dev.) }\end{array}$ & $\begin{array}{l}\text { mean } \\
\text { (std. dev.) }\end{array}$ \\
\hline \multirow[t]{3}{*}{$12 / 13$} & architecture & $3.47(0.91)$ & $4.06(0.54)$ & $3.50(0.83)$ & $3.77(0.87)$ & $3.50(0.83)$ \\
\hline & $\begin{array}{l}\text { civil } \\
\text { engineering }\end{array}$ & $3.92(0.99)$ & $3.75(0.44)$ & $3.29(1.29)$ & $4.01(0.79)$ & 3.29 (1.29) \\
\hline & $\begin{array}{l}\text { building } \\
\text { science }\end{array}$ & $3.75(1.06)$ & $3.38(1.00)$ & $3.09(0.84)$ & $3.57(0.89)$ & $3.02(0.30)$ \\
\hline \multirow[t]{3}{*}{$13 / 14$} & architecture & $3.58(0.77)$ & $3.44(0.93)$ & $3.19(1.23)$ & $2.94(1.22)$ & 3.19 (1.23) \\
\hline & $\begin{array}{l}\text { civil } \\
\text { engineering }\end{array}$ & $3.88(0.65)$ & $3.62(0.67)$ & $3.25(0.79)$ & $4.01(0.71)$ & $3.25(0.79)$ \\
\hline & $\begin{array}{l}\text { building } \\
\text { science }\end{array}$ & $2.95(1.13)$ & $3.45(0.54)$ & $3.31(0.93)$ & $3.93(0.62)$ & $3.21(0.77)$ \\
\hline \multirow[t]{3}{*}{$14 / 15$} & architecture & $3.08(0.88)$ & $4.19(0.44)$ & $3.77(0.25)$ & $4.15(0.58)$ & $3.77(0.25)$ \\
\hline & $\begin{array}{l}\text { civil } \\
\text { engineering }\end{array}$ & $3.12(0.83)$ & $3.75(0.46)$ & $3.34(0.35)$ & $4.33(0.49)$ & $3.34(0.35)$ \\
\hline & $\begin{array}{l}\text { building } \\
\text { science }\end{array}$ & $3.47(0.77)$ & $2.78(0.78)$ & $2.77(0.65)$ & $2.98(1.17)$ & $2.77(0.65)$ \\
\hline
\end{tabular}

might have influenced their work and results so they could not meet their aspirations.

Concerning the software constructs Kruskal-Wallis tests indicate significant differences in the perceived ease of use between the nine groups $\left(\mathrm{X}^{2}=14.266, \mathrm{df}=8, \mathrm{p}=0.0751\right)$, as well as for perceived usefulness $\left(\mathrm{X}^{2}=21.095, \mathrm{df}=8, \mathrm{p}=0.0069\right)$ and also interoperability $\left(\mathrm{X}^{2}=50.617, \mathrm{df}=8\right.$, $\mathrm{p}<0.001$ ). Pairwise Wilcox rank sum tests (with alpha error adjustment using the Bonferoni-Holm method to account for alpha error accumulation due to multiple comparisons) were used as post hoc tests. For EU the evaluation of building scientists in $14 / 15$ is significantly lower from architects $14 / 15(\mathrm{p}=0.0069)$. For UF post hoc tests indicated no significant differences. However, for building science $14 / 15$ evaluated the interoperability of the software significantly worse than all other eight groups (at least $\mathrm{p}<0.05$ ). Furthermore civil engineering in 13/14 evaluated interoperability significantly better than building science in the previous year 12/13. All other evaluations are not significantly different at $\mathrm{p}<0.05$.

Figure 4 shows the results of the content analysis of the focus group discussions with the participants at the end of the interdisciplinary building design project. In total, across the three BIM iterations we kept the same - initially developed - 13 category scheme to insure a proper comparison of the gathered data, see Table 3. For the purpose of this paper we consider just the relative frequency of relevant content categories and omit the categories 


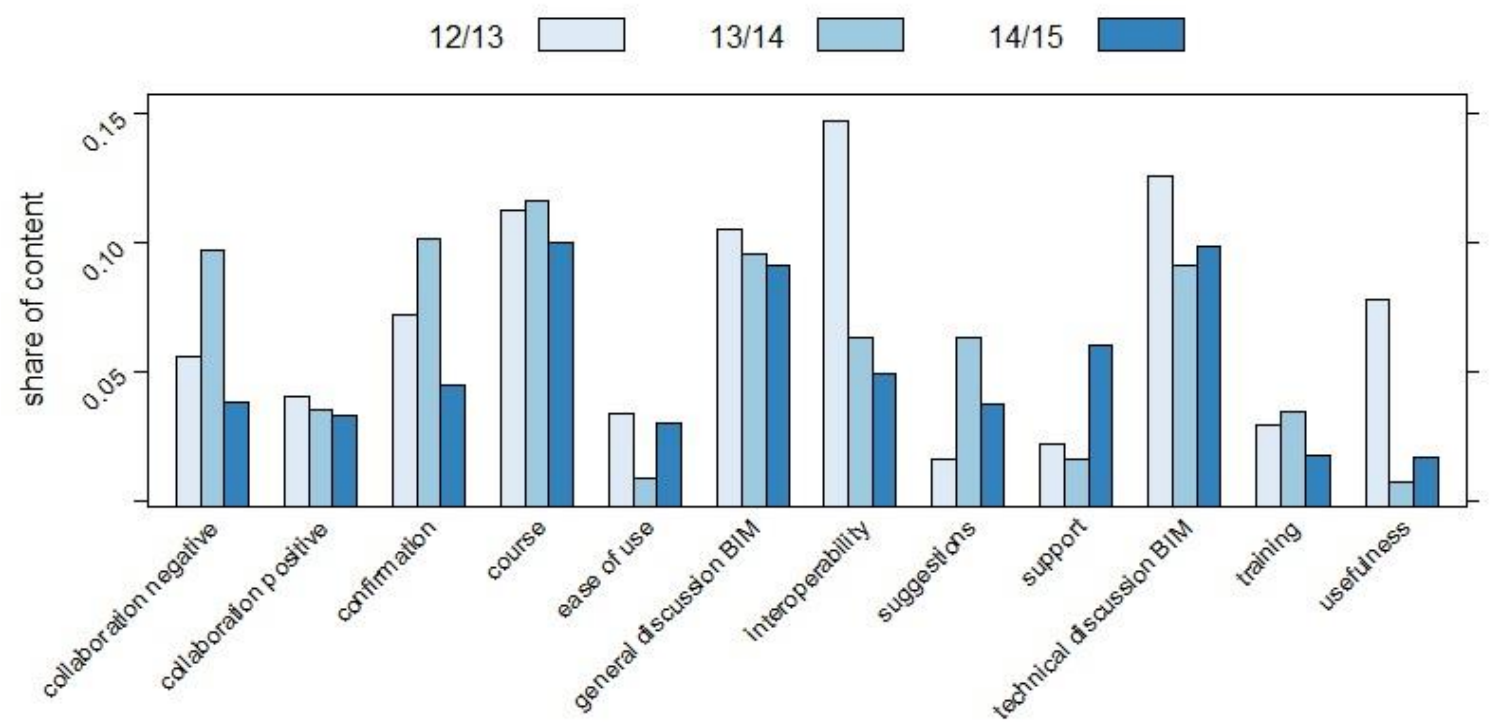

Figure 4: Content analysis of focus group discussions

'miscellaneous' and 'moderation' which cover off topic communication and the moderation parts like asking questions or active listening by the moderator - of the focus group discussion. The other 11 categories are presented in Figure 4.

In the focus group discussions - in all three iterations general discussions about BIM and its relevance in education and practice were a major topic. The participants of all disciplines and in all iterations used around $10 \%$ of the coded thought units (excluding the category miscellaneous and moderation) talking about this topic, as well as topics related to the IDS at the Vienna University of Technology and detailed issues on how to realize BIM with the software at hand (modeling conventions, etc.). The technology part of BIM was not discussed in detail and therefore of minor importance for the participants except the interoperability aspect for the different software solutions. In the first focus group there were many complaints about lacking interoperability, in the second and third iterations the topic became - as the other software related topics - a minor issue, too, after the software constellations were restricted to those known to work together well. Concerning the discussions of collaboration in the team the negative examples outweigh the positive ones.
The above presented results base on the participants' self evaluation in form of the questionnaires and on the content analysis of the feedback gathered in the focus group discussions. The instructors' observations coincided in the majority of the cases with the students' evaluations, besides one considerable difference. The quality of and satisfaction with the outcomes of the projects was evaluated superior by students compared to the instructors' evaluation (Kovacic et al., 2015). This could be explained by the different perspectives and expectations between students' and instructors'. While the actual design quality was inferior the students also took into account that they had to learn new software and software functionalities and had to learn to cooperate in a multidisciplinary team. Given these additional tasks the achieved designs were satisfactory from the perspective of the participants.

\section{Discussion and conclusion}

This paper evaluated the challenges of BIM adoption by means of observing the results and developments of a BIM-supported IDS at the Vienna University of Technology. Different assignments of tasks and course designs while holding constant the methods of measurement and 
evaluation allow for analyzing influencing factors on satisfaction and performance.

The analyses reveal that the participants in general appreciate the collaborative approach, and benefit from working with other disciplines by sharing knowledge. The relevance of BIM for teaching and practice in general, as well as the technical modeling details and the specific course features at the Vienna University of Technology were major topics in the group discussions. Software and collaboration on the other hand only played a minor role and negative statements about the lack of collaboration and interoperability dominated slightly the discussions. Interoperability of the software solutions ceased from being a major topic (in the first iteration) after the software constellations were restricted to those involving more compatible software constellations and moreover could be chosen by the participants themselves. Therefore in the iterations in winter term 2013 and 2014, interoperability ranked as low as ease of use and usefulness of software while being the most important topic in winter term 2012 . The issue of software is important to BIMcollaboration - if it does not work as promised and as expected it seems. Concerning the evaluation of the questionnaires we found very high evaluation of the usefulness of the applied software followed by lower evaluations of ease of use and lowest interoperability. Though architects state in the focus group discussions that their low evaluation of cooperation results from the early intervention of the other disciplines in the design phase which was sensed stressing and restricting, we found no explanation for the development on the side of the civil engineers in the transcripts of the focus group discussions. The course settings, such as introductory teaming workshop or reduction of assignment size, had no observable effects on outcome satisfaction, which remained fairly constant over the iterations of the course. However, as the anova revealed, satisfaction differed significantly between the disciplines. The disciplines that are involved in the project earlier, which are the architects and the civil engineers are more satisfied with the outcome than the building scientists who typically take over the initiative only at later stages. These results can be explained by the lower influence on the outcome and the higher time pressure that coincides with a later involvement in the project. The proximity to the semester end and therefore the project deadline requires sacrifices in outcome quality which lowers especially the building scientists' satisfaction with their results, as learned from the focus group discussions with this discipline. It is very significant, that the first statements - and therefore most pressing topics - on the opening question 'How did you experience the building planning process in the BIM project?' in the focus groups with the building scientists in 13/14 (BIM_studio) and 14/15 (BIM_meridean) as well as the second statement in the first building scientists focus group 12/13 (BIM_sustain) addressed exactly this topic:

"There should be milestones what work should be done until when and then a part of the work has to be finished and that is given to the structural engineers or us [remark: the building scientists] and then it would work better" (building scientists focus group BIM_sustain 12/13). "Most of our workload was at the end of the semester, like December [...] we had to wait for the architects to build the first plan. " (building scientists focus group BIM_station 13/14). The participants complain that the architects continuously change the model which costs project time and requires adaption efforts for the simulations of the building scientists. Most explicitly these problems were addressed in the first statement of the building scientists focus group after the third iteration "There was so much time spent by the architects and the structural engineers [...] and then there is so little time for us to develop our concept. The architects always seem to spend time on the building and geometry and this held our part back, it makes us waiting" (building scientists focus group BIM_meridean 14/15).

This low outcome satisfaction of building scientists demonstrates that disciplines are still caught in the traditional, sequential planning process rationale, which is present in the specific curricula and thus taught at universities, which still follows traditional inter-professional interactions. Therefore, in order to change the professional silo-thinking and achieve a cultural shift in AEC practice, education of new generations of professionals based on a 
collaborative approach and multidisciplinary platforms, such as the presented IDS is necessary.

As course instructors and moderators of the focus group discussions we observed in the process of developing and further-developing the BIMsupported IDS at the Vienna University of Technology a set of interwoven challenges that need to be considered to avoid frustration of students and instructors. In all courses so far expectations about the capabilities, interoperability and the state of the art of the software used for BIM were quite high. This is not surprising as BIM is promoted as the future technology in specialist literature and also in the course discussion in the first class of the IDS. However, the deficiencies of existing software combined with a lack of knowledge of and experience with the relevant functions often causes difficulties in the exchange of models. A lot of effort or even redrawing of models then is necessary to at least finish the tasks in time. In a BIM course this can be frustrating for the students that expect to learn how BIM works, just to see that is does not work as it should. Support at all levels, software support but also supporting the groups in the first model exchange attempts, is important to avoid frustration. Moreover, from the very beginning of the course expectations of the participants need to be kept a realistic level in our opinion. We emphasized the importance of modeling conventions and the exchange of simplified models. Groups that followed these suggestions were able to observe the potential of the approach and not only current the limitations of the software.

Another observation is an overestimation of the effects of an integrated design approach by the participants in the course. By training and from their experience in the majority of the other courses during their studies, interdisciplinary collaboration and teamwork often is not usual. Structural engineers and building scientist often expect a building model as an input for their work. In the integrated design process these disciplines often state that it was interesting to see how these building models evolved and what the guiding ideas behind them were. However, for the architects the negative effects of integrated design can outweigh the positive effects. Especially, if architects expect early inputs and suggestions but in some cases, also due to lack of experience in this form of cooperation in the early design phase, do not receive them or even perceive the suggestions by others as interrupting and restricting.

Similarly, to these varying discipline philosophies, the nature of the task and perception of time of the disciplines involved in integrated planning process are different, which need to be considered in the design of the course, the planning task and the support of the participants both in terms of software and project support. During their studies architects through the whole semester typically focus on building design and geometry. During their courses they develop and improve the final architectural model in an iterative process. Therefore, based on custom and past experience, architects can feel pressured by civil engineers and building scientist that are used to receive a model as input which the can work on in their simulations and analyses. If these input models come late, change often and then also cannot be imported easily, but need to be redrawn in the worst case, this can cause frustration and conflict potential. Our suggestion for this challenge is to define a milestone with a fixed date for the architectural model mid of the semester and adjust the extent of the project and the requirements so that this deadline can be kept.

Based on our observations as course instructors and through coupling and analysis of qualitative and quantitative data, and evaluation of three consequent cohorts of IDSs we can conclude that a) due to the education system, students are trained in a mono-disciplinary manner, and seldom confronted with collaborative work throughout the course of their studies; and b) such education is building the basis for later professional attitudes in practice. Literature on BIM argues that BIM bears potentials to bring more integration into the fragmented AEC practice, furthermore, a need for the introduction of a framework for BIM as product and process modeling and a need for organizational change are claimed (Succar, 2009). However, our research points out that successful implementation of BIM is not only coupled with process and organizational change, but more basically is directly related education. 
As a future research step, feedback from the former graduates, acting as change agents in the industry, should be allow to gain insight in the actual impact of such courses on practice. Other studies on BIM in education show similar results, despite the fact that these studies focus either (i) on BIM in later planning stages - i.e. detailed design or construction (Peterson et al., (2010); Hyatt (2010); Dossik (2012)) - or (ii) primarily on the issues of technology, in terms of interoperability (Poerscheke et al., (2010); Plume and Mitchel, (2007)). Authors conclude that BIM tools are beneficial for analysis and quantification, but for actual process and design quality improvement, people related issues are relevant, such as working experience or interdisciplinary cooperation as driver of creativity. Thereby a change of professional culture towards a more collaborative practice should be pursued in the education, adopting novel, interdisciplinary approaches, such as IDS, instead of incorporating traditional rationales. This is exactly the research gap that the IDS tries to fill. Through repeated investigations and more students joining the course, we plan to influence the view on interdisciplinary work by showing the advantages and benefits of working in joint teams rather than using the classical sequential approach, nevertheless we do not conceal the challenges and problems that could arise based on our experience.

We conclude, that in order to change the way students and later professionals tackle the difficulties of integrated planning, fundamental changes are necessary. A semantic change in education has to occur, changing the role of the architect, civil engineer and building scientist from independent actors to being pro-active part of the design-team. What is needed in the practice has to be taught at universities. Sustainable improvement of the situation in the AEC industry depends on improvements in academic education - by multidisciplinary IDSs as those developed in this series of experiments at the Vienna University of Technology. Moreover, direct implications for the practice can be derived from the observations of the experiment. Amongst others, the main findings from the experiments relevant for practice are: (i) though cooperation is important, it is difficult - an additional and explicit role for coordination activities (in experiments often assumed by the architects) has to be established. (ii) Even if industry standards - like Industry Foundation Classes (ifc) - exist, not all of the software solutions following these standards are equally interoperable - software choice and modeling conventions are important and need to be addressed prior to the start of the collaboration to save, rather than cause additional, costs and time.

\section{References}

Amor, R. and Ma, H. (2006). Preservation of meaning in mapped IFCs. Proceeding, 6th European Conference on Product and Process Modeling (ECPPM), Valencia, Spain: 233-236.

Chien K.-F., Wu Z.-H., Huang S.-C., (2014) "Identifying and assessing critical risk factors for BIM projects: Empirical study," Automation in Construction, 45, 1-15

Dainty A., Leiringer R., Fernie S., Harty C., (2015) "Don't Believe the (BIM) Hype: The Unexpected Corollaries of the UK 'BIM Revolution'”, Working Paper Proceedings, Engineering Project Organization Conference The University of Edinburgh, Scotland, UK June 24-26, 2015

Davis, F. D. (1989) "Perceived usefulness, perceived ease of use, and user acceptance of information technology", MIS Quarterly, 13(3), 319-340.

Dossick C., Anderson A., Iorio J., Gina Neff G., Taylor J., (2012) „Messy Talk and Mutual Discovery: Exploring the Necessary Conditions for Synthesis in Virtual Teams", Engineering Project Organizations Conference, Rheden, The Netherlands.

Eadie R., Browne M., Odeyinka H., McKeown C., McNiff S. (2013) "BIM implementation throughout the UK construction project lifecycle: An analysis," Automation in Construction 36, 145-151

Hackman, J. R., and Morris, C. G. (1975). Group tasks, group interaction process, and group performance effectiveness: A review and proposed integration, Academic Press, New York.

Hyatt A. (2011) “A Case Study Integrating Lean, Green, BIM into an Undergraduate Construction Management Scheduling", 47th ASC Annual International Conference Proceedings.

Jeong Y.S., Eastman C.M., Sacks, R., Kaner I. (2009) „Benchmark tests for BIM data exchanges of precast concrete", Automation in Construction, 18, 469-484.

Kiviniemi A., Fischer M., Bazjanac V. (2005) „Integration of Multiple Product Models: IFC Model Server as a Potential Solution“, Proc. of the 22nd 
CIB-W78 Conference on Information Technology in Construction.

Kovacic I, Filzmoser M, Kiesel K., Oberwinter L., Mahdavi A., (2015) "BIM teaching as support to integrated design practice"; Gradevinar, 67(6), 537 546.

Kovacic I., Filzmoser M. (2014), "Designing and evaluation procedures for interdisciplinary building information modeling use-an explorative study", Engineering Project Organization Journal, 1, 1 - 8 .

Krueger, R. A. and Casey, M. A. (2009) "Focus groups. A Practical Guide for Applied Research", Sage, Los Angeles.

Peterson F., Hartmann T., Fruchter R., Fischer M., (2011) "Teaching construction project management with BIM support: Experience and lessons learned", Automation in Construction, 20, 115 - 125.

Plume, J, Mitchell, J (2007). "Collaborative design using a shared IFC building model-Learning from experience". Automation in Construction, 16, 28 36.

Poerscheke U., Holland R.J., Messner J.I., Philak M., (2010) "BIM collaboration across disciplines", Proceedings of the International Conference on Computing in Civil and Building Engineering.

Rohrbaugh, J. (1988). "Cognitive conflict tasks and small group processes." Advances in Psychology, 54, 199-226.

Simon, H. A. (1960). The new science of management decision, Harper and Brothers, New York.

Srnka, K. J. and Koeszegi, S. T. (2007) "From words to numbers: How to transform qualitative data into meaningful quantitative results", Schmalenbach Business Review, 59, 29 - 57.

Succar B. (2009) ,Building information modelling framework: A research and delivery foundation for industry stakeholders", Automation in Construction, 18, 357-375. 